\title{
Education, Marriage, and Employment in People with Epilepsy: The Barriers that Patients Perceive
}

\author{
Ali A. Asadi-Pooya ${ }^{1,2}$ Maryam Homayoun ${ }^{1}$ \\ ${ }^{1}$ Epilepsy Research Center, Shiraz University of Medical Sciences, \\ Shiraz, Iran \\ ${ }^{2}$ Department of Neurology, Jefferson Comprehensive Epilepsy \\ Center, Thomas Jefferson University, Philadelphia, Pennsylvania, \\ United States
}

Int J of Ep:2020;6:50-53

\author{
Shahla Keshavarz ${ }^{1}$
}

\begin{abstract}
Address for correspondence Ali A. Asadi-Pooya, MD, Epilepsy Research Center, Shiraz University of Medical Sciences, Shiraz, Iran (e-mail: aliasadipooya@yahoo.com, maryam.homayoun@gmail.com, sheida.keshavarzi@gmail.com).
\end{abstract}

\begin{abstract}
Keywords

- education

- epilepsy

- marriage

- seizure

Objectives We surveyed people with epilepsy (PWE) and uncontrolled seizures on the challenges which they have had in their lives with respect to educational achievement, employment, and marriage. We tried to scrutinize their reasons and perceptions for their social underachievement and difficulties.

Materials and Methods Adult patients above 25 years of age, with epileptic seizures for more than 5 years, who were investigated at Shiraz Comprehensive Epilepsy Center, from January until March 2019, were studied. We prepared a questionnaire for our study and asked whether they have any college education? If they have ever married? And, if they are employed?

Results Seventy patients enrolled in our study. Age of the patients was $33 \pm 6$ years (range: 26-59 years) and their age at onset of epilepsy was $14 \pm 9$ years (range: $0-35$ years). Forty-four patients (63\%) never received any college education; 30 patients (43\%) were single; and finally, 37 patients (53\%) were unemployed. The most common reasons perceived by the patients for these life challenges were functional disability (e.g., inability to study or to work), social discrimination and stigmatization, and uncontrolled seizures and the associated consequences (i.e., fear of having seizures).

Conclusion Many PWE (both men and women) and uncontrolled seizures suffer from social underachievement and challenges in their daily lives. Various strategies may help PWE to overcome these challenges.
\end{abstract}

\section{Introduction}

Epilepsy is often associated with stigma and functional disability $^{1}$; as a result, people with epilepsy (PWE) often have social (e.g., marriage and educational achievement) and economic (e.g., employment) challenges in their daily lives. In one previous study in Tanzania, ${ }^{1}$ the authors observed that young PWE were more likely to experience employment difficulties, and educational and relationship problems in the transition to their adult lives than controls, with the greatest disadvantage experienced by females and those with bad seizure control. ${ }^{1}$ In another study from Nigeria, ${ }^{2}$ the authors observed that women with epilepsy had worse social and economic status when compared with women with other nonstigmatized chronic medical conditions. This observation has been reproduced in other studies. ${ }^{3}$

Many studies have investigated marriage, educational achievement, and employment in PWE, ${ }^{4,5}$ but few have scrutinized the patients' perceptions of the challenges they face with regards their daily lives. In the current study, we surveyed PWE with uncontrolled seizures on the challenges which they have had in their lives with respect to educational achievement, employment, and marriage. We tried
DOI https://doi.org/ 10.1055/s-0040-1715767 ISSN 2213-6320. (c) 2020. Indian Epilepsy Society.

This is an open access article published by Thieme under the terms of the Creative Commons Attribution-NonDerivative-NonCommercial-License, permitting copying and reproduction so long as the original work is given appropriate credit. Contents may not be used for commercial purposes, or adapted, remixed, transformed or built upon. (https://creativecommons.org/licenses/by-nc-nd/4.0/)

Thieme Medical and Scientific Publishers Pvt. Ltd., A-12, 2nd Floor, Sector 2, Noida-201301 UP, India 
to scrutinize their reasons and perceptions for their social underachievement and difficulties.

\section{Materials and Methods}

In the current survey, adult patients above 25 years of age, with epileptic seizures for more than 5 years since the onset, who were investigated at Shiraz Comprehensive Epilepsy Center at Shiraz University of Medical Sciences, from January until March 2019, were studied if they consented to participate. We made the diagnosis of epilepsy after a careful clinical assessment and electroencephalogram recording. Patients with at least one seizure in the past 12 months, despite receiving antiepileptic drugs (AEDs) were included (defined as having uncontrolled seizures). We selected patients above 25 years of age to ensure that men have passed the age for mandatory army service (which makes them eligible for employment) and also considering the average age of marriage in Iran. ${ }^{6}$

We prepared a questionnaire for our study and we collected the following information anonymously at the time of admission: age, age at onset, sex, education, list of AEDs, and experiencing any seizures in the past 12 months. We also included three multiple choice questions in the questionnaire (patients could select more than one answer):

1. Do you have any college education? If not, why (inability to study, fear of having a seizure at school, parental disagreement, financial reasons, others)?

2. Have you ever married? If not, why (nobody agreed to marry me, fear of having a seizure, fear of pregnancy and medical problems for my child, parental disagreement, financial reasons, others)?

3. Are you employed? If not, why (inability to work, fear of having a seizure at work, nobody employs me, parental or spousal disagreement, I am a housewife, others)?

We performed univariate analyses using Pearson's Chi-square and $t$-test. A $p$-Value less than 0.05 was considered as significant. This study was conducted with the approval by Shiraz University of Medical Sciences Review Board.

\section{Results}

During the study period, 70 patients ( 39 males and 31 female patients) enrolled in our study. Age of the patients was $33 \pm$ 6 years (range: $26-59$ years) and their age at onset of epilepsy was $14 \pm 9$ years (range: $0-35$ years). The duration of their illness was $19 \pm 9$ years (range: $5-39$ years). They had $51 \pm 157$ seizures (range: 1-1,095) during the past 12 months (history-wise; no seizure diary). Twenty-six patients (37\%) were on monotherapy and 44 patients (63\%) were on polytherapy with AEDs. Forty-four patients (63\%) never received any college education; 30 patients (43\%) were single; and 37 patients (53\%) were unemployed. Reasons they provided for not having a college education are shown in - Table $\mathbf{1}$. Having a college education was positively associated with employment; $17 / 26$ (65\%) of patients with and 16/44 (36\%) of patients without a college education were employed
Table 1 Reasons for not having a college education reported by patients with epilepsy

\begin{tabular}{|l|l|}
\hline Reason & Number (\%) \\
\hline Financial reasons & $17(24)$ \\
\hline Inability to study & $13(19)$ \\
\hline Fear of having a seizure at school & $11(16)$ \\
\hline Other reasons* & $12(17)$ \\
\hline
\end{tabular}

*7 people were not interested, 4 people reported marriage, and in one person the parents disagreed, as the reason.

Table 2 Reasons for being single reported by patients with epilepsy

\begin{tabular}{|l|l|}
\hline Reason & Number (\%) \\
\hline Nobody had agreed to marry me & $10(15)$ \\
\hline Financial reasons & $9(13)$ \\
\hline Fear of having a seizure & $8(11)$ \\
\hline $\begin{array}{l}\text { Fear of pregnancy and medical prob- } \\
\text { lems for my child }\end{array}$ & $4(6)$ \\
\hline Other reasons* & $15(21)$ \\
\hline
\end{tabular}

${ }^{*} 7$ people were not interested, 4 people reported marriage, and in one person the parents disagreed, as the reason.

Table 3 Reasons for unemployment reported by patients with epilepsy

\begin{tabular}{|l|l|}
\hline Reason & Number (\%) \\
\hline Fear of having a seizure at work & $11(16)$ \\
\hline Inability to work & $9(13)$ \\
\hline Nobody employs me & $8(11)$ \\
\hline I am a housewife & $10(14)$ \\
\hline Other reasons* & $6(9)$ \\
\hline
\end{tabular}

*7 people were not interested, 4 people reported marriage, and in one person the parents disagreed, as the reason.

$(p=0.02)$. Sex $(p=1)$ was not associated with any college education. Reasons they provided for being single are shown in - Table 2. Marital status did not have any significant associations with sex $(p=0.3)$, college education $(p=0.4)$, and employment $(p=0.3)$. Reasons they provided for being unemployed are shown in $\mathbf{- T a b l e} \mathbf{3}$. When we excluded the housewives from the analyses, employment was not significantly associated with sex $(p=0.06)$.

\section{Discussion}

In this study, we observed that many PWE (both men and women) and uncontrolled seizures suffer from social underachievement and challenges in their daily lives; about two-thirds did not receive any college education; more than two-fifths were not married; and more than half were unemployed. These figures are consistent with those from previous studies. ${ }^{1,4}$

The most common reasons perceived by the patients for not having college education were financial reasons, inability 
to study, and fear of having a seizure at school. In a previous qualitative interview and focus group study involving teachers, parents, and young PWE, ${ }^{7}$ behavioral problems and learning difficulties (consistent with "inability to study" in the current work) were cited as the main barriers to education for young PWE. ${ }^{7}$

The singulate mean age at marriage (the average length of single life expressed in years among those who marry before age 50 ) in Iran is 23.5 years among women and 26.8 years among men. ${ }^{8,9}$ Therefore, it is to some extent surprising to observe that $43 \%$ of our patients (with a mean age of 33 years [range: 26-59 years]) were not married. The most common reasons perceived by the patients for not being married were social discrimination and stigmatization (nobody had agreed to marry me), financial reasons, and fear of having a seizure. Previous studies have confirmed negative views within the general public for PWE to marry..$^{10}$ In a previous study of 800 respondents in north Iran, ${ }^{11}$ the authors found that only $28 \%$ of the respondents were willing to accept their family member's marriage to someone with epilepsy.

The most common reasons perceived by the patients in our study for not being employed were fear of having a seizure at work, inability to work, and social discrimination and stigmatization (nobody employs me). Many factors may negatively affect the employability of PWE, including clinical (e.g., uncontrolled seizures and fear of having a seizure), psychological (e.g., stigma), socioeconomic (e.g., lower educational level), and political (e.g., driving restrictions) factors. ${ }^{4}$ One study of all adult patients with epilepsy in the Swedish patient register in 2000 to $2015(n=126,406)$ and controls $(n=379,131)$ matched for age, gender, and place of birth, showed that while low educational attainment was associated with low levels of income and inversely associated with employment in both PWE and controls, these associations were much more noticeable in PWE than controls. ${ }^{12}$ One study showed that higher education level, higher self-determination, lower family overprotection, and generalized epilepsy were significant predictors for higher employability in PWE. ${ }^{13}$ PWE may benefit from vocational rehabilitation services; of the 2,030 previously unemployed PWE in one study, who received vocational rehabilitation services, 884 (43.5\%) achieved successful competitive employment. ${ }^{14}$

In conclusion, many patients with epilepsy and uncontrolled seizures may suffer from employment difficulties, and educational and relationship problems in their lives. The most common reasons perceived by the patients in our study for these life challenges were functional disability (e.g., inability to study or to work), social discrimination and stigmatization, and uncontrolled seizures and the associated consequences (including, fear of having seizures). The underlying brain disorder in PWE and also adverse effects of AEDs used by these patients are possible reasons for functional disability among PWE. Considering the high prevalence of functional disabilities (e.g., learning difficulties) among PWE, routine screening of all PWE for early detection and appropriate management of any cognitive dysfunction and functional disability would be a reasonable approach. ${ }^{15,16}$
However, these findings should be seen and interpreted in the context of sociocultural backgrounds. For example, in 2019, Iran's unemployment rate was estimated to be $12 \%$ of the total labor force ${ }^{17}$ this is much lower than the $53 \%$ rate in PWE in the current study.

Vocational rehabilitation services would particularly be helpful to those who are unemployed and perceive that they have an inability to work. ${ }^{14}$ Various strategies may help PWE to overcome the stigma and discrimination that is imposed on them because of their medical condition. Support groups and increasing knowledge in the general population are among the important strategies to help PWE to overcome stigma and discrimination. ${ }^{11}$ Finally, for PWE and uncontrolled seizures, delivering appropriate care may be particularly advantageous; in one previous study, ${ }^{18}$ the authors observed that among unemployed PWE with uncontrolled seizures, who had epilepsy surgery, better seizure outcome after surgery was associated with gaining employment at 2 years.

This study has some limitations. Employment was based on the self-report and we did not specify the definition of it (e.g., full- vs. part-time employment). In addition, we did not investigate the socioeconomic situation of the families of the patients.

\section{Conflict of Interest}

A.A.A.P received honoraria from Cobel Daruo and royalty from Oxford University Press. Other authors declare no conflict of interest.

\section{Acknowledgment}

We appreciate the Neuroscience Research Center, Shiraz University of Medical Sciences, for supporting this study.

\section{References}

1 Goodall J, Salem S, Walker RW, et al. Stigma and functional disability in relation to marriage and employment in young people with epilepsy in rural Tanzania. Seizure 2018;54:27-32

2 Komolafe MA, Sunmonu TA, Afolabi OT, et al. The social and economic impacts of epilepsy on women in Nigeria. Epilepsy Behav 2012;24(1):97-101

3 Birbeck G, Chomba E, Atadzhanov M, Mbewe E, Haworth A. The social and economic impact of epilepsy in Zambia: a cross-sectional study. Lancet Neurol 2007;6(1): 39-44

4 Wo MC, Lim KS, Choo WY, Tan CT. Employability in people with epilepsy: a systematic review. Epilepsy Res 2015;116:67-78

5 Puka K, Tavares TP, Speechley KN. Social outcomes for adults with a history of childhood-onset epilepsy: a systematic review and meta-analysis. Epilepsy Behav 2019;92:297-305

6 Average marriage age in Iran increased by 3 years. Available at: https://www.tehrantimes.com/news/424338/Average-marriageage-in-Iran-increased-by-3-years/. Accessed on December 3, 2019

7 Quereshi C, Standing HC, Swai A, Hunter E, Walker R, Owens S. Barriers to access to education for young people with epilepsy in Northern Tanzania: a qualitative interview and focus group study involving teachers, parents and young people with epilepsy. Epilepsy Behav 2017;72:145-149

8 Ever married men and women, Singulate Mean Age at Marriage (SMAM). Available at: http://data.un.org/DocumentData.aspx?id=321/. Accessed May 12, 2020 
9 Mean age at first marriage, singulate mean age at marriage and percentage ever married by age group. Available at: https:// www.un.org/en/development/desa/population/publications/ dataset/fertility/wfr2012/Metadata/Metadata_MAFM-SMAMEVER-MARRIED.pdf/. Accessed May 12, 2020

10 Kinariwalla N, Sen A. The psychosocial impact of epilepsy on marriage: a narrative review. Epilepsy Behav 2016;63: 34-41

11 Ghanean H, Nojomi M, Jacobsson L. Public awareness and attitudes towards epilepsy in Tehran, Iran. Glob Health Action 2013;6:21618

12 Andersson K, Ozanne A, Edelvik Tranberg A, et al. Socioeconomic outcome and access to care in adults with epilepsy in Sweden: a nationwide cohort study. Seizure 2020;74:71-76

13 Wo MC, Lim KS, Choo WY, Tan CT. Factors affecting the employability in people with epilepsy. Epilepsy Res 2016;128:6-11

14 Sung C, Muller V, Jones JE, Chan F. Vocational rehabilitation service patterns and employment outcomes of people with epilepsy. Epilepsy Res 2014;108(8):1469-1479
15 Auvin S, Wirrell E, Donald KA, et al. Systematic review of the screening, diagnosis, and management of ADHD in children with epilepsy. Consensus paper of the Task Force on Comorbidities of the ILAE Pediatric Commission. Epilepsia 2018;59(10): $1867-1880$

16 Wo SW, Ong LC, Low WY, Lai PSM. The impact of epilepsy on academic achievement in children with normal intelligence and without major comorbidities: a systematic review. Epilepsy Res 2017;136:35-45

17 Iran: Unemployment rate from 1999 to 2020. Available at: https://www.statista.com/statistics/294305/iran-unemployment-rate/. Accessed May 15, 2020

18 Chin PS, Berg AT, Spencer SS, et al. Employment outcomes following resective epilepsy surgery. Epilepsia 2007;48(12): 2253-2257 